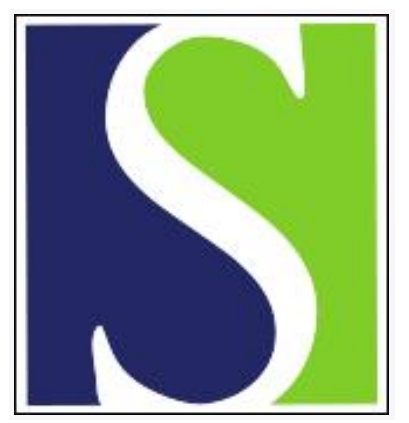

Scand J Work Environ Health 2012;38(4):370-379

https://doi.org/10.5271/sjweh.3195

Published online: 14 Sep 2011, Issue date: 01 Jul 2012

Governmental regulations for early retirement by means of energy expenditure cut offs

by Wultsch G, Rinnerhofer S, Tschakert G, Hofmann P

Affiliation: Human Performance Research Graz, Karl-Franzens-University \& Medical University Graz, Max Mell Alle 11, AT-8010 Graz, Austria. peter.hofmann@uni-graz.at

Refers to the following texts of the Journal: 1991;17 suppl 1:7-11 2007;33(6):405-424 1991;17 suppl 1:99-109 1997;23 suppl 1:66-71

Key terms: early retirement; energy expenditure; gas exchange measure; heart rate monitoring; heavy workload; retirement; retirement plan

This article in PubMed: www.ncbi.nlm.nih.gov/pubmed/21918790 


\title{
Governmental regulations for early retirement by means of energy expenditure cut offs
}

\author{
by Georg Wultsch, MD, ${ }^{1}$ Stefan Rinnerhofer, MSc, ${ }^{2}$ Gerhard Tschakert, Dr, ${ }^{3}$ Peter Hofmann, Dr ${ }^{2,3}$
}

\begin{abstract}
Wultsch G, Rinnerhofer S, Tschakert G, Hofmann P. Governmental regulations for early retirement by means of energy expenditure cut offs. Scand J Work Environ Health. 2012:38(4):370-379. doi:10.5271/sjweh.3195

Objectives Long-term heavy work impairs employees, and they may retire prematurely by law. We investigated the value of energy expenditure (EE) during work shifts as a means to define heavy workload.

Methods The study comprised 79 male [mean age 32.2 (standard deviation [SD] 7.5) years] and 33 female [33.5 (SD 11.2) years] employees in different occupations classified as "heavy work" (EE of 1400 and $2000 \mathrm{kcal}$ for women and men, respectively). Cycle ergometry determined exercise performance. Gas exchange measures were performed during selected phases of work, and heart rate (HR) recordings were obtained for a complete work shift. EE was calculated from gas exchange measures.
\end{abstract}

Results Male and female subjects differed significantly for maximal power output $\left(\mathrm{P}_{\max }\right)$ [men=206.3 (SD 47.3) watts; women=149.6 (SD 36.1) watts] and maximal oxygen consumption $\left(\mathrm{VO}_{2 \max }\right)[\mathrm{men}=2.965$ (SD 0.63) 1/min; women= $1.958(\mathrm{SD} 0.50) \mathrm{l} / \mathrm{min}]$ in the cycle ergometer test. Shift $\mathrm{HR}\left(\mathrm{HR}_{\mathrm{Sh}}\right)$ was found between $102(\mathrm{SD}$ 14) $\mathrm{b} / \mathrm{min}\left[57.6\right.$ (SD 8.5) percentage of maximal HR (\% $\left.\left.\mathrm{HR}_{\max }\right)\right]$ and 99 (SD 10) b/min $\left[55.5\right.$ (SD 5.9) \% $\left.\mathrm{HR}_{\max }\right]$ dependent on tasks and groups. Working EE was found between 1864 (SD 732) kcal and 1249 (SD 609) kcal for men and women, respectively, but approximately $60 \%$ of subjects were well below the legal limits.

Conclusions The legal definition of heavy workload by mean working EE per 8-hour work shift applies to all investigated occupations; however, a substantial proportion of workers may not fulfill the criterion if applied individually. Alternative definitions of heavy workload in terms of absolute oxygen consumption or EE relative to cardiorespiratory fitness lead to similar classification results of the investigated occupations.

Key terms gas exchange measures; heavy workload; heart rate monitoring; retirement plan.

The working population over 50 years of age will grow considerably $(1,2)$; however, work ability mainly for high-demanding work may not increase to the same extent and is even expected to decrease (3). Especially hard work and shift work are related to higher risk of cardiovascular disease and early retirement (4-6), which is a major social problem in most western countries. Hannerz et al (7) nicely showed that hard physical work is an independent risk factor for disability retirement and, from this point of view, employees performing hard work for prolonged time may be allowed to retire earlier than usual applying defined rules for retirement. Karpansalo et al $(8,9)$ showed that physical fitness was significantly associated with the risk of disability pension among employees presenting a maximal oxygen consumption $\left(\mathrm{VO}_{2 \max }\right)<26 \mathrm{ml} / \mathrm{kg} / \mathrm{min}$ who had a 4.66fold risk of disability pension due to cardiovascular disease.

In order to regulate early retirement, several parameters have been applied to define workload in some European countries. In these concepts, physical working capacity plays a major role. The main variable used is $\mathrm{VO}_{2}$ during work, which is suggested to be the most important factor defining hard work. Hard work may, therefore, be defined as being in the range of $33-50 \%$ of $\mathrm{VO}_{2 \max }(10)$, an overall acceptable limit avoiding anaerobic metabolism during work (11-13). Additionally, Bink (14) suggested that one third of the maximal aerobic capacity is acceptable for energy expenditure (EE) during eight hours of work.

1 Arbeitsmedizinisches Zentrum, Graz, Austria.

2 Institute of Sports Science, Karl-Franzens-University Graz, Austria.

3 Human Performance Research Graz, Karl-Franzens-University and Medical University Graz, Austria.

Correspondence to: Dr Peter Hofmann, Human Performance Research Graz, Karl-Franzens-University \& Medical University Graz, Max Mell Alle 11, AT-8010 Graz, Austria. [E-mail: peter.hofmann@uni-graz.at] 
Another alternative to define hard work is the absolute $\mathrm{VO}_{2}$ during occupation measured in $1 / \mathrm{min}$. In defining hard work that should not be exceeded, Astrand et al (15) suggested a limit of 1 litre of $\mathrm{VO}_{2}$

In 2006, an Austrian law concerning job-related early retirement (16) was established stemming from demographic changes that can be seen in all European countries $(17,18)$. In line with these changes, rules for early retirement were adapted with respect to life-long hard workload including a new definition of hard work by means of shift work EE (16). Comparable to the tables of Spitzer et al (19), the lower limit for hard work was set at a workload equivalent to $2000 \mathrm{kcal}(8374 \mathrm{~kJ})$ per day for men and $1400 \mathrm{kcal}(5862 \mathrm{~kJ})$ for women, independent of age, whereas working EE is generally calculated as total EE minus resting EE. Different jobs assuming hard work above a target of 2000/1400 kcal for working EE have been listed by law (16) including jobs in the meat processing, health services, and metal industries. Furthermore, masseuses and female physiotherapists are occupations with EE $>1400 \mathrm{kcal}$. However, in this list some occupations are not defined as being above the targets although employees may be included due to their individual workload profile. Conversely, employees in jobs with workloads defined as being above the targets of hard workload may actually be below these limits due to individual reasons such as training and age (11).

Therefore, the need for large scale investigations on workload-dependent EE measures is evident (20-23). Usually, EE during work is assessed according to the standards of industrial medicine applying norm tables (19) or calculated from heart rate (HR) measures (24).

The aim of this study was, therefore, to directly measure EE and HR among male and female employees to evaluate the legal definitions of hard work and their applicability to different groups of occupations.

\section{Methods}

The study group included 112 (79 male and 33 female) healthy volunteers. The subjects investigated were 19-56-year-old healthy employees performing work with mostly physical demands (table 1 ), recruited by the local occupational health service. Subjects worked in meat processing slaughterhouse work, the metal industry, healthcare services, and waste processing. Occupational tasks of these four groups were classified according to the International Standard Classification of Occupation (ISCO) (25). Subjects were recruited by their typical work, which was chosen to be representative of the occupational task, and by the distribution between male and female workers typical for the occu- pation under study. Although females are less frequently employed in slaughterhouse work, two women were included in this study to depict the workload of female workers in this occupation. The results of these two female workers were only included in mean female group descriptive statistics and figures.

The anthropometric characteristics of subjects are presented in table 1. The study was performed according to the Helsinki Declaration and a written informed consent was obtained from the participants. An ethics committee agreement was given. None of the subjects regularly used medication. Additionally, study participants had to have no history of significant musculoskeletal, neurological, metabolic or cardiopulmonary pathology and no physical illness during the last three months; this was controlled exclusively by the leading physician of the study.

\section{Maximal aerobic power output}

After thorough medical examination and an ECG at rest, subjects performed a maximal incremental cycle ergometer exercise test on an electronically braked, computer controlled ergo meter (Monark 839E, Monark Exercise AB, Sweden) to determine maximal aerobic power output $\left(\mathrm{P}_{\max }\right)$. The exercise test started at 20 watts (W) for women or $40 \mathrm{~W}$ for men, dependent on fitness level, and workload was increased by $15 \mathrm{~W} / \mathrm{min}$. This protocol is within the recommendations of the American College of Sports Medicine to determine $\mathrm{P}_{\max }$ among young and physically active individuals (26) and is the standard protocol of the Austrian Society of Cardiology (27). The choice of this ramp-like protocol allowed for an accurate determination of the first and the second ventilatory threshold $\left(\mathrm{VT}_{1}\right.$ and $\left.\mathrm{VT}_{2}\right)(28,29)$. $\mathrm{HR}$ was continuously measured during the test and up to five minutes after the test; blood pressure was measured every minute. A 12-lead ECG was conducted continuously during exercise and recovery. $\mathrm{VO}_{2}$ and carbon dioxide $\left(\mathrm{CO}_{2}\right)$ output were measured continuously using a breath by breath ergospirometric system (Metamax $3 \mathrm{~B}$, Cortex Biophysik, Germany). The $\mathrm{O}_{2}$ and $\mathrm{CO}_{2}$ sensors were calibrated by standard gases according to the manufacturer's guidelines before the tests. The triple-V turbine was calibrated using a 3-litre syringe before testing. Blood lactate concentration was measured at rest, at the end of every load step, and during recovery. Capillary blood samples $(20 \mu \mathrm{l})$ were taken from the hyperemized ear lobe and blood lactate concentration was determined encymatically (Biosen S-Line; EKFDiagnostic, Germany).

Subjects were verbally encouraged to continue the test until they could no longer maintain the given crank frequency of $70 \mathrm{rpm} . \mathrm{VO}_{2 \max }$ was taken as the average of the highest five consecutive breaths attained in the last 


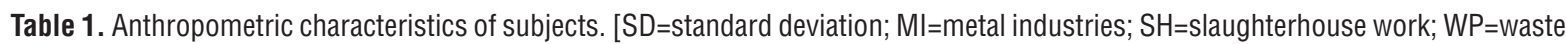
processing; $\mathrm{HC}=$ healthcare business; $\mathrm{BMI}=$ body mass index]

\begin{tabular}{|c|c|c|c|c|c|c|c|c|c|}
\hline & \multirow[t]{2}{*}{$\mathrm{N}$} & \multicolumn{2}{|c|}{ Age (years) } & \multicolumn{2}{|c|}{ Height (m) } & \multicolumn{2}{|c|}{ Weight (kg) } & \multicolumn{2}{|c|}{$\mathrm{BMI}\left(\mathrm{kg} / \mathrm{m}^{2}\right)$} \\
\hline & & Mean & SD & Mean & SD & Mean & SD & Mean & SD \\
\hline Female $_{\text {all }}$ & 33 & 33.5 & 11.2 & 1.64 & 0.06 & 64.2 & 13.5 & 23.8 & 4.6 \\
\hline Male $_{\text {all }}$ & 79 & 32.2 & 7.5 & 1.78 & 0.06 & 80.8 & 11.6 & 25.6 & 3.9 \\
\hline Female $_{\mathrm{MI}}$ & 9 & $37.7^{\mathrm{a}}$ & 11.0 & 1.63 & 0.05 & 67.2 & 16.2 & 25.3 & 5.4 \\
\hline Male $_{\mathrm{MI}}$ & 31 & $33.3^{a}$ & 8.2 & 1.75 & 0.06 & 79.1 & 10.9 & 25.7 & 3.6 \\
\hline Female $_{\mathrm{SH}}$ & 2 & 40.9 & 5.1 & 1.60 & 0.04 & 53.5 & 0.7 & 20.9 & 1.4 \\
\hline Male $_{S H}$ & 31 & $33.8^{b}$ & 7.3 & $1.79^{c}$ & 0.06 & 85.2 & 11.7 & 26.6 & 4.2 \\
\hline Female $_{\mathrm{HC}}$ & 14 & 23.8 & 3.5 & 1.66 & 0.06 & 63.9 & 12.1 & 23.1 & 4.4 \\
\hline Male $_{\mathrm{HC}}$ & 9 & 25.2 & 2.6 & 1.80 & 0.04 & 77.8 & 6.6 & 23.9 & 1.8 \\
\hline Female $_{W P}$ & 8 & $44.0^{d}$ & 8.4 & 1.63 & 0.05 & 64.1 & 14.1 & 24.2 & 4.5 \\
\hline Male $_{w P}$ & 8 & 29.7 & 6.2 & 1.78 & 0.05 & 74.2 & 13.0 & 23.4 & 4.6 \\
\hline
\end{tabular}

a Significant difference $\mathrm{Ml} / \mathrm{HC}$.

${ }^{\mathrm{b}}$ Significant difference MI / WP.

c Significant difference MI / SH.

d Significant difference HC / WP.

minute of exercise. $\mathrm{VT}_{1}$ was defined as the workload at the minimum for the equivalent for $\mathrm{O}_{2}\left(\mathrm{VE} / \mathrm{VO}_{2}\right)$ without an increase in the equivalent for $\mathrm{CO}_{2}\left(\mathrm{VE} / \mathrm{VCO}_{2}\right)$ (30). $\mathrm{VT}_{2}$ was defined as the increase of both $\mathrm{VE} / \mathrm{VO}_{2}$ and $\mathrm{CO}_{2} \mathrm{VE} / \mathrm{VCO}_{2}$.

Each subject's individual performance was described as percentage of age-predicted standard $\mathrm{P}_{\max }$ and $\mathrm{VO}_{2 \max }$ uptake according to standard equations (27).

\section{Heart rate and energy expenditure during work}

Each subject's HR was measured during one whole 8 -hour shift $\left(\mathrm{HR}_{\mathrm{Sh}}\right)$ by means of a portable HR monitor (Polar S810; Polar Electro, Finland) storing HR every 5 seconds.

During 20 minutes of representative task-specific periods of work, $\mathrm{VO}_{2}$ and $\mathrm{CO}_{2}$ production were determined by means of breath - by breath gas exchange analysis using a portable system (MetaMax 3B, Cortex Biophysik, Germany) on every subject. The $\mathrm{O}_{2}$ and $\mathrm{CO}_{2}$ sensors were calibrated using standard gases of known concentration according to the manufacturer's guidelines. The triple- $\mathrm{V}$ turbine was calibrated using a 3.0-litre syringe before testing. The subjects' HR was recorded separately by means of a HR monitoring system integrated into the portable device of the spirometer system.

Mean respiratory exchange ratio (RER) was calculated from $\mathrm{VO}_{2}$ and $\mathrm{CO}_{2}$ production. Mean $\mathrm{VO}_{2}$ multiplied by the caloric equivalent taken from standard tables (31) matched for the mean respiratory exchange ratio was used to calculate the amount of $\mathrm{EE}$ for the observed time span. The total energy consumption for a whole work shift was calculated as EE per minute multiplied by the duration of the individual shift. This was possible due to the specific nature of the kind of shift work investigated with more or less the same work tasks during the whole shift and corrected for mean $\mathrm{HR}_{\mathrm{Sh}}$.
Work-related EE was calculated by subtracting resting $\mathrm{EE}$ from the total $\mathrm{EE}$ calculated from the gas exchange measures. The resting EE was calculated for each subject by means of Mifflin's formula (32).

\section{Statistical analysis}

Data are presented as means and standard deviation (SD). The Kolmogorov-Smirnov test was used to test normal distribution. Analysis of variance (ANOVA) and Tukey's post hoc analysis were used to calculate means of between-group differences, and linear regressions analysis and Pearson's product moment correlation were used to calcuated the relationship between variables. All calculations were performed using Winstat statistics (Winstat, Kalmia Corp Cambridge, MA, USA). A level of $\mathrm{P}<0.05$ was considered significant.

\section{Results}

Male and female subjects did not differ significantly for age and body mass index (BMI), but did for height and body mass. Within occupation groups, male and female subjects differed significantly for age but not for body mass and height in most cases (table 1).

\section{Incremental cycle ergometer exercise test}

The results from the incremental cycle ergometer exercise test are presented in tables 2 and $3 . \mathrm{P}_{\max }$ for all subjects was found to be significantly different between male [206.3 (SD 47.3) W] and female [149.6 (SD 36.1) W] subjects, similar to $\mathrm{VO}_{2 \max }$ which was 2.965 (SD 0.630) $1 / \mathrm{min}$ and 1.958 (SD 0.499) $1 / \mathrm{min}$ for men and women, respectively. 
Mean values for body-mass-related $\mathrm{O}_{2}$ uptake were significantly different between male and female employees at 37.3 (SD 9.2) $\mathrm{ml} / \mathrm{kg} / \mathrm{min}$ and 31.1 (SD 7.6) $\mathrm{ml} / \mathrm{kg} /$ min for men and women, respectively. $\mathrm{VO}_{2 \max }$ was significantly different between occupation groups whereas older employees presented lower $\mathrm{VO}_{2 \max }$ values. $\mathrm{VO}_{2 \max }$ was within reference limits (27) except for female subjects in the metal and waste processing industries, which were lower. Subjects in healthcare were at the upper range of the reference limits.

No significant difference was detected for maximum RER, which was 1.20 (SD 0.11) and 1.20 (SD 0.08) for women and men, respectively, indicating that subjects equally reached their limits of exercise during the test. Maximal blood lactate concentration was not significantly different between male and female subjects at $7.02(\mathrm{SD} 1.54) \mathrm{mmol} / \mathrm{l}$ and 6.80 (SD 1.60) $\mathrm{mmol} / \mathrm{l}$ for men and women, respectively (table 2).

Maximal HR ( $\left.\mathrm{HR}_{\max }\right)[\mathrm{men}=178.1$ (SD 13.1) b/min; women=179.0 (SD 16.8) b/min] was not found to be significantly different between male and female subjects, and mean values were close to age predicted $\mathrm{HR}_{\max }$ [men=100.2 (SD 6.6) \%; women=99.0 (SD 6.2) \%]. $\mathrm{HR}_{\max }$ was significantly related to age among both male and female subjects (figure 1) and subgroups were different in $\mathrm{HR}_{\max }$ dependent on age (table 2).

Power output, $\mathrm{O}_{2}$ uptake, and $\mathrm{HR}$ at $\mathrm{VT}_{1}$ were, respectively, 39.1 (SD 6.0) \%, 50.7 (SD 6.3) \%, and 68.4 (SD 4.6) \% of maximal values among men and 36.9 (SD 6.6) \%, 55.0 (SD 8.2) \%, and 70.9 (SD 4.5) \% among women (table 3). At $\mathrm{VT}_{2}$ power output, $\mathrm{O}_{2}$ uptake and HR were, respectively, 74.9 (SD 7.2) \%, 79.4 (SD 5.3) \%, and 86.7 (SD 3.7) \% of maximal values among men and 75.6 (SD 4.7) \%, 82.6 (SD 5.5) $\%$, and 89.3 (SD 3.4) \% among women (table 3). Percentage of $\mathrm{P}_{\max }$ at $\mathrm{VT}_{1}$ and $\mathrm{VT}_{2}$ were not significantly different between male and female subjects, however, $\% \mathrm{VO}_{2 \max }$ and $\% \mathrm{HR}_{\text {max }}$ were.

All subjects had normal blood pressure and ECG readings (data not shown).

\section{Heart rate and energy expenditure during occupation}

Data for the different task-specific activities and groups are depicted in table 4. Mean heart rate during a whole shift $\left(\mathrm{HR}_{\mathrm{Sh}}\right)$ [mean acquisition time 7.35 (SD 0.30) hours] was not significantly different between men and women and was 102.1 (SD 14.4) b/min and 98.8 (SD 9.5) $\mathrm{b} / \mathrm{min}$ for men and women, respectively, for all groups. Mean $\mathrm{HR}_{\mathrm{Sh}}$ was between 57.6 (SD 8.5) \% and 55.5 (SD 5.9) \% (not significantly different) of $\mathrm{HR}_{\max }$ from the incremental exercise test. Mean $\mathrm{HR}_{\mathrm{Sh}}$ related to $\mathrm{HR}$ at $\mathrm{VT}_{1}$ was significantly different between male and female subjects and was 84.3 (SD 11.9) \% and 78.7 (SD 10.4) \% for men and women, respectively (table 4).
As expected, measured $\mathrm{HR}_{\max }$ declined with age both among men and women (figure 1). The relationship between $\% \mathrm{HR}_{\max }$ during the shift and maximal workload reached in the incremental exercise test was significant for male and female subjects (figure 2) whereas fitter subjects had significantly lower $\% \mathrm{HR}_{\max }$ values during their work.

HR during the short phase (20 minutes each) of EE measurement and mean HR during the whole 8-hour shift were slightly but significantly higher by 4.7 (SD 9.8) b/min among men and 2.6 (SD 9.8) b/min among women (figure 3 ).

$\mathrm{O}_{2}$ uptake measured during 20 minutes of representative work was significantly different between male and female employees at 1.13 (SD 0.35) $1 / \mathrm{min}$ and 0.73 (SD 0.29) $1 / \mathrm{min}$ for men and women, respectively. However relative $\mathrm{O}_{2}$ uptake during these various occupational tasks was not significantly different at 39.4 (SD 13.7) \% and 38.2 (SD 13.9) \% for men and women, respectively, of the maximal relative $\mathrm{O}_{2}$ uptake from the incremental exercise test (table 5) which was significantly below $\mathrm{VT}_{1}$ values.

The calculated EE for the task-specific groups is presented in table 5. Average total EE was found to be significantly different between male and female subjects at 1695 (SD 638) kcal and 2451 (SD 735) kcal for women and men, respectively. Working EE (total EE minus resting EE) was calculated as 1249 (SD 609) kcal and 1864 (SD 732) kcal for women and men, respectively, (significant difference between the genders). Overall $44.3 \%$ (men) and $36.4 \%$ (women) of subjects were found to be above the given limits.

Calculating total $\mathrm{EE}$ from $\mathrm{VO}_{2}$ data from the ergometer test at comparable $\mathrm{HR}$ to the mean $\mathrm{HR}_{\mathrm{Sh}}$ gave a significantly different EE between the genders of 1740 (SD 376) kcal for women and 2309 (SD 782) kcal for men, but there was only a slight but not significant difference between measured and calculated total EE of $4.9 \%$ (men) and $4.7 \%$ (women).

The well-trained healthcare group subjects were found to be below the reference limit of $33 \% \mathrm{VO}_{2 \max }$ (9) whereas all other groups were above this limit and therefore in a range described to be the maximum recommended relative aerobic strain for an 8-hour shift. Twelve male and seven female employees $(17.0 \%)$ were $>50 \% \mathrm{VO}_{2 \max }$.

During incremental exercise, $76(96.2 \%)$ male and $13(39.4 \%)$ female employees presented a $\mathrm{VO}_{2 \max }$ uptake $>21 /$ min $(15, \mathrm{p} 521)$. Comparing oxygen uptake during work with the absolute limit of $1 \mathrm{l} / \mathrm{min}$ according to Astrand et al (15), 50 (63.3\%) male and $4(12.1 \%)$ female subjects were above this limit during their work, but oxygen uptake was not related to exercise performance (figure 4). 
Table 2. Physiological characteristics from incremental cycle ergometer exercise. [ $P_{\max }=$ maximal power output; $\mathrm{VO}_{2 \max }=\operatorname{maximal}$ oxygen consumption; $\mathrm{HR}_{\max }=$ maximal heart rate; $\mathrm{La}_{\max }=$ maximal lactate concentration; $\mathrm{RER}_{\max }=$ maximal respiratory exchange ratio; $\mathrm{MI}=\mathrm{metal}$ industries; $\mathrm{SD}=$ standard deviation; $\mathrm{SH}=$ slaughterhouse work; WP=waste processing; $\mathrm{HC}=$ healthcare business]

\begin{tabular}{|c|c|c|c|c|c|c|c|c|c|c|c|}
\hline & \multicolumn{3}{|c|}{$P_{\max }$ (watts) } & \multicolumn{2}{|c|}{$\mathrm{VO}_{2 \max }(\mathrm{I})$} & \multicolumn{2}{|c|}{$\mathrm{HR}_{\text {max }}$ (minutes) } & \multicolumn{2}{|c|}{$\mathrm{La}_{\max }(\mathrm{mmol} / \mathrm{l})$} & \multicolumn{2}{|c|}{$\mathrm{RER}_{\max }$} \\
\hline & $\mathrm{N}$ & Mean & SD & Mean & SD & Mean & SD & Mean & SD & Mean & SD \\
\hline Females & 33 & 149.6 & 36.1 & 1.958 & 0.499 & 179.0 & 16.8 & 6.80 & 1.60 & 1.20 & 0.11 \\
\hline Males & 79 & 206.3 & 47.3 & 2.965 & 0.630 & 178.1 & 13.1 & 7.02 & 1.54 & 1.20 & 0.08 \\
\hline Female $_{\mathrm{MI}}$ & 9 & 128.1 & 22.9 & 1.600 & 0.289 & 165.4 & 13.3 & 6.34 & 1.12 & 1.23 & 0.11 \\
\hline Male $_{\mathrm{MI}}$ & 31 & 179.1 & 27.9 & 2.579 & 0.407 & 175.0 & 12.8 & 6.65 & 1.16 & 1.17 & 0.08 \\
\hline Female $_{\mathrm{SH}}$ & 2 & 135.0 & 14.1 & 1.513 & 0.330 & 170.0 & 2.8 & 6.66 & 0.74 & 1.35 & 0.12 \\
\hline Male $_{S H}$ & 31 & $201.0^{a}$ & 23.1 & $2.906^{a}$ & 0.341 & 173.7 & 10.4 & 6.63 & 0.93 & 1.22 & 0.09 \\
\hline Female $_{\mathrm{HC}}$ & 14 & $181.4^{b, c}$ & 26.4 & $2.346^{b, c}$ & 0.387 & $194.2^{b, c}$ & 6.1 & 7.86 & 1.63 & 1.14 & 0.07 \\
\hline Male $_{\mathrm{HC}}$ & 9 & 295.0 b,d,c & 58.6 & $4.088^{b, d, c}$ & 0.639 & $197.9 \mathrm{~b}, \mathrm{~d}$ & 3.3 & $9.20^{b, d, c}$ & 2.32 & 1.16 & 0.05 \\
\hline Female $_{\text {WP }}$ & 8 & 121.6 & 19.1 & 1.792 & 0.418 & 169.8 & 14.0 & 5.51 & 0.91 & 1.25 & 0.11 \\
\hline Male $_{W P}$ & 8 & $233.1^{\mathrm{e}}$ & 23.9 & 3.429 e,f & 0.396 & 184.8 & 8.6 & 7.49 & 1.79 & 1.22 & 0.07 \\
\hline
\end{tabular}

a Significant difference $\mathrm{MI} / \mathrm{SH}$.

b Significant difference Ml / HC.

c Significant difference HC / WP.

a Significant difference SH / HC.

e Significant difference MI / WP.

${ }^{\dagger}$ Significant difference SH / WP.

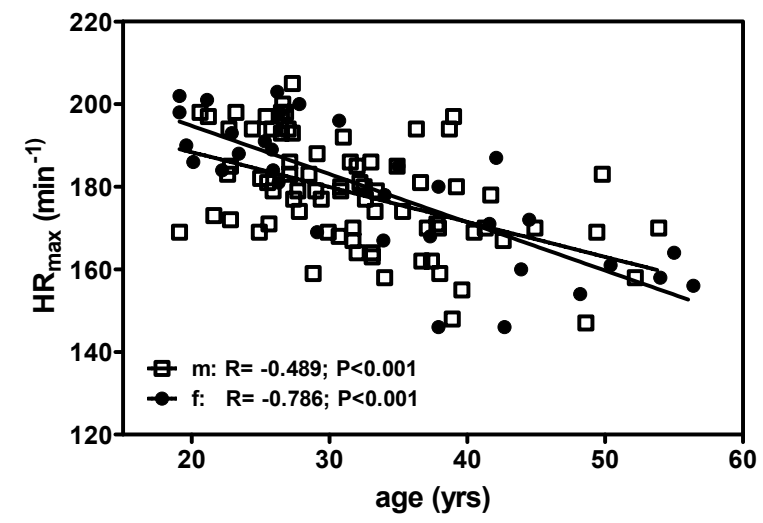

Figure 1. Age related decline in maximal heart rate $\left(\mathrm{HR}_{\max }\right)$ among male (m) and female (f) employees.

\section{Discussion}

Exercise performance of subjects was within reference limits (27), except for male metal industry and slaughterhouse workers who were found to be below these limits. Male and female subjects in healthcare and female subjects in slaughterhouse work were trained and clearly at the upper range of the reference limits. HR during a typical 8-hour shift was well below an acceptable HR limit of $110 \mathrm{~b} / \mathrm{min}$ (33). EE was found to be within the limits of the definition of hard work. When applying Austrian law, however, $55.7 \%$ of the male and $63.6 \%$ of the female employees were below these limits, but a substantial number of subjects were above the limits for hard work.

Jorgensen (13) has investigated several possibili- ties to define permissible workloads. Applying ergonomic standards stating that $95 \%$ of employees should not exceed the $35 \% \mathrm{VO}_{2 \max }$ limit consequently will define most occupations with physical work as hard work and will substantially increase the proportion of employees allowed to retire earlier. In our opinion, having $95 \%$ of the employees within the limits of $35 \% \mathrm{VO}_{2 \max }$ is far too high. However, most manual workers are unable to reach normal retirement age because of (often job-related musculoskeletal and cardiovascular disease) health problems or an age-related decrease in cardiorespiratory fitness $(3,7-11)$. These workers are currently punished by retirement regulations that heavily and disproportionally reduce the pension amount of persons who retire before they reach the legal retirement age $(5,6)$. To balance the costs of early retirement and necessary compensations for employees performing hard work, the legislative body needs to specify the percentage of workers in any occupation above the limits for hard work in order to regulate early retirement. Another approach is to define this limit for specific groups within the labor force. The best option described is to determine the $\mathrm{VO}_{2 \max }$ of the individual worker in pre-employment investigations. However, this requires resources and knowledge and will offend generally accepted ethical and political viewpoints concerning employee selection and recruitment of the labor force (13).

It is important to note that absolute EE is not a feasible criterion to define hard work, due to its dependence on individual body weight and fitness level.

According to Ilmarinen (11), the upper limit for short-term heavy workloads (including brakes) should not exceed $50 \%$ of maximum aerobic strain, which equals our $\mathrm{VT}_{1}$ (table $3 \mathrm{~b}$ ), a workload that does not activate anaerobic metabolism (11). 
Table 3a. Heart rate (HR), Power (P) output and oxygen uptake $\left(\mathrm{VO}_{2}\right)$ from incremental cycle ergometer exercise at $\mathrm{VT}_{1}$ (first ventilatory turn point) and $\mathrm{VT}_{2}$ (second ventilatory turn point). [ $\mathrm{SD}=$ standard deviation; $\mathrm{MI}=$ metal industries; $\mathrm{SH}=$ slaughterhouse work; $\mathrm{WP}=$ waste processing; $\mathrm{HC}=$ healthcare business]

\begin{tabular}{|c|c|c|c|c|c|c|c|c|c|c|c|c|}
\hline & \multicolumn{2}{|c|}{$\mathrm{HR}_{\mathrm{VT1}}$ (minutes) } & \multicolumn{2}{|c|}{$\mathrm{HR}_{\mathrm{VT2}}$ (minutes) } & \multicolumn{2}{|c|}{$\mathrm{P}_{\mathrm{VT1}}$ (watts) } & \multicolumn{2}{|c|}{$\mathrm{P}_{\mathrm{VT2}}$ (watts) } & \multicolumn{2}{|c|}{$\mathrm{VO}_{2 \text { vT1 }}$ (liters) } & \multicolumn{2}{|c|}{$\mathrm{VO}_{2 \text { VT2 }}($ liters $)$} \\
\hline & Mean & SD & Mean & SD & Mean & SD & Mean & SD & Mean & SD & Mean & SD \\
\hline Females & 127.2 & 16.4 & 160.2 & 19.3 & 55.2 & 17.0 & 113.8 & 31.1 & 1.067 & 0.270 & 1.615 & 0.425 \\
\hline Males & 121.8 & 12.5 & 154.5 & 14.8 & 81.6 & 26.6 & 155.0 & 41.1 & 1.509 & 0.415 & 2.355 & 0.552 \\
\hline Female $_{\mathrm{MI}}$ & 114.6 & 10.1 & 145.6 & 13.2 & 43.0 & 12.2 & 96.7 & 18.5 & 0.869 & 0.228 & 1.308 & 0.186 \\
\hline Male $_{\text {MI }}$ & 121.1 & 13.5 & 153.2 & 13.8 & 68.8 & 15.4 & 131.9 & 27.9 & 1.251 & 0.219 & 2.032 & 0.271 \\
\hline Female $_{\mathrm{SH}}$ & 114.0 & 8.5 & 145.0 & 4.2 & 46.5 & 9.2 & 100.0 & 14.1 & 0.890 & 0.095 & 1.254 & 0.252 \\
\hline Male $_{S H}$ & 116.7 & 8.3 & 147.5 & 9.9 & 78.8 & 18.6 & 149.7 & 20.1 & 1.513 a & 0.243 & $2.292^{\mathrm{a}}$ & 0.318 \\
\hline Female $_{\mathrm{HC}}$ & $140.6^{b, c}$ & 10.8 & $179.1^{\mathrm{b}, \mathrm{c}}$ & 7.3 & $69.0 \mathrm{~b}, \mathrm{c}$ & 13.3 & $140.2^{b, c}$ & 23.7 & $1.255^{b}$ & 0.242 & $1.960 \mathrm{~b}, \mathrm{c}$ & 0.354 \\
\hline Male $_{\mathrm{HC}}$ & $139.3^{b, d, c}$ & 7.5 & $179.2^{b, c, c, d}$ & 4.0 & $125.6^{b, c, d}$ & 33.7 & $232.9^{b, c, d}$ & 43.0 & $2.206^{b, c, d}$ & 0.567 & $3.405 \mathrm{~b}, \mathrm{c}, \mathrm{d}$ & 0.642 \\
\hline Female $_{W P}$ & 121.3 & 14.7 & 147.1 & 12.1 & 47.0 & 11.0 & 90.3 & 20.4 & 1.003 & 0.145 & 1.449 & 0.314 \\
\hline Male $_{\text {WP }}$ & 124.9 & 8.5 & 159.3 & 11.7 & $92.5^{\mathrm{e}}$ & 23.1 & $177.8^{\mathrm{e}}$ & 21.6 & $1.713^{\mathrm{e}}$ & 0.282 & 2.668 e,f & 0.332 \\
\hline
\end{tabular}

a Significant difference MI / SH.

b Significant difference Ml / HC.

c Significant difference HC / WP.

d Significant difference SH / HC.

e Significant difference MI / WP.

' Significant difference SH / WP.

Table 3b. Percentage of maximal values of heart rate $(\mathrm{HR})$, power $(\mathrm{P})$ output and oxygen uptake $\left(\mathrm{VO}_{2}\right)$ from incremental cycle ergometer exercise at $\mathrm{VT}_{1}$ (first ventilatory turn point) and $\mathrm{VT}_{2}$ (second ventilatory turn point). [MI=metal industries; $\mathrm{SD}=$ standard deviation; $\mathrm{SH}=$ slaughterhouse work; $\mathrm{WP}=$ waste processing; $\mathrm{HC}=$ healthcare business]

\begin{tabular}{|c|c|c|c|c|c|c|c|c|c|c|c|c|}
\hline & \multicolumn{2}{|c|}{$\% \mathrm{HR}_{\mathrm{VT} 1}$ (minutes) } & \multicolumn{2}{|c|}{$\% \mathrm{HR}_{\text {VT2 }}$ (minutes) } & \multicolumn{2}{|c|}{$\% \mathrm{P}_{\mathrm{VT1}}$ (watts) } & \multicolumn{2}{|c|}{$\% \mathrm{P}_{\text {VT2 }}$ (watts) } & \multicolumn{2}{|c|}{$\% \mathrm{VO}_{2 \mathrm{VT} 1}$ (liters) } & \multicolumn{2}{|c|}{$\% \mathrm{VO}_{2 \text { VT2 }}$ (liters) } \\
\hline & Mean & SD & Mean & SD & Mean & SD & Mean & SD & Mean & SD & Mean & SD \\
\hline Females & 70.9 & 4.4 & 89.3 & 3.4 & 36.9 & 6.5 & 75.6 & 4.7 & 55.0 & 8.1 & 82.6 & 5.5 \\
\hline Males & 68.4 & 4.6 & 86.7 & 3.7 & 39.1 & 5.9 & 74.9 & 7.2 & 50.7 & 6.3 & 79.4 & 5.3 \\
\hline Female $_{\mathrm{MI}}$ & 69.2 & 2.6 & 87.9 & 2.7 & 34.1 & 9.1 & 75.4 & 3.4 & 54.5 & 10.8 & 82.3 & 5.6 \\
\hline Male $_{\mathrm{Ml}}$ & 69.2 & 5.6 & $87.5^{a}$ & 3.3 & 38.2 & 5.1 & 73.7 & 10.4 & 48.8 & 6.9 & 79.2 & 4.9 \\
\hline Female $_{S \mathrm{H}}$ & 67.1 & 4.3 & 85.3 & 2.8 & 35.0 & 7.4 & 73.9 & 1.9 & 59.6 & 4.7 & 83.0 & 1.0 \\
\hline Male $_{\mathrm{SH}}$ & 67.2 & 3.6 & 85.0 & 3.4 & 38.9 & 6.4 & 74.5 & 3.8 & 52.0 & 4.7 & 78.9 & 6.1 \\
\hline Female $_{\mathrm{HC}}$ & 72.4 & 4.9 & 92.2 & 1.9 & 38.0 & 4.4 & 77.0 & 3.2 & 53.5 & 5.4 & 83.4 & 4.8 \\
\hline Male $_{\mathrm{HC}}$ & 70.4 & 3.3 & $90.6^{b, c}$ & 1.6 & 42.4 & 4.7 & 79.2 & 3.0 & 53.7 & 7.9 & 83.0 & 3.7 \\
\hline Female $_{W P}$ & 71.3 & 4.0 & 86.7 & 2.0 & 38.4 & 4.7 & 73.6 & 7.0 & 57.2 & 8.2 & 81.3 & 6.7 \\
\hline Male $_{W P}$ & 67.6 & 3.4 & 86.2 & 3.9 & 39.5 & 6.8 & 76.1 & 2.0 & 49.9 & 4.4 & 77.8 & 2.4 \\
\hline
\end{tabular}

a Significant difference MI / SH.

b Significant difference SH / HC.

c Significant difference HC / WP.

Wu \& Wang (12) showed in their laboratory experiment among Taiwanese young adults that the maximum acceptable work time for continuous cycle ergometer work with 10 minute breaks every hour was clearly limited to $<8$ hours when exceeding $34 \%$ of $\mathrm{VO}_{2 \max }$. These authors therefore suggested the limit of maximum acceptable workload for 8 hours of continuous cycle ergometer work to be about $34 \% \mathrm{VO}_{2 \max }(12)$. Our own data showed a slightly higher average percentage of $\mathrm{O}_{2}$ uptake during work of 39.4 (SD 13.7) \% and 38.2 (SD 13.9) \% among men and women, respectively. As the investigated occupations in our study were different from those in the demanding continuous cycling exercise, we suggest that the workload of our study participants was not as hard as that described by Wu \& Wang (12). Additionally, the workload was clearly below the limits described by Ilmarinen (11), and we may thus define the investigated occupations as hard work even though a certain proportion of employees were also below these limits.

Female employees presenting low exercise performance in the incremental cycle test had also low EE during work, whereas the male employees with low $\mathrm{P}_{\max }$ showed high EE during work. This may suggest a different strategy of work among men and women or simply the fact that male employees perform the more strenuous work that strains unfit subjects to a greater extent.

Several industrialized countries discuss regulations on heavy work that would be applied for retirement 
Table 4. Heart rate during one work shift $\left(H R_{S h}\right)$ and percentage of maximal heart rate $\left(\% H R_{\max }\right)$ from incremental ergometer exercise. [HC=healthcare business; $\mathrm{HR}_{20}=$ heart rate during 20 minutes of energy expenditure (EE) measurement; $\mathrm{Ml}=$ metal industries; $\mathrm{SD}=$ standard deviation; $\mathrm{SH}=$ slaughterhouse work; WP=waste processing.]

\begin{tabular}{|c|c|c|c|c|c|c|c|}
\hline & \multirow[t]{2}{*}{ N } & \multicolumn{2}{|c|}{ Mean $\mathrm{HR}_{\mathrm{Sh}}$ (minutes) } & \multicolumn{2}{|c|}{$\% \mathrm{HR}_{\max }$} & \multicolumn{2}{|c|}{ Mean $\mathrm{HR}_{20}$ (minutes) } \\
\hline & & Mean & SD & Mean & SD & Mean & SD \\
\hline Females & 33 & 98.8 & 9.5 & 55.5 & 5.9 & 104.4 & 12.4 \\
\hline Males & 79 & 102.1 & 14.4 & 57.6 & 8.5 & 108.3 & 16.4 \\
\hline Female $_{\mathrm{MI}}$ & 9 & 95.1 & 6.2 & 57.7 & 4.6 & 100.1 & 14.6 \\
\hline Male $_{\mathrm{Ml}}$ & 31 & $105.9^{a, b}$ & 10.3 & $60.8^{a, b}$ & 6.7 & $114.4^{a, b}$ & 14.7 \\
\hline Female $_{\mathrm{SH}}$ & 2 & 100.5 & 3.5 & 59.1 & 1.1 & 102.5 & 7.8 \\
\hline Male $_{\mathrm{SH}}$ & 31 & 97.3 & 12.2 & $56.1^{c}$ & 6.9 & 103.5 & 13.0 \\
\hline Female $_{\mathrm{HC}}$ & 14 & 100.3 & 11.2 & 54.6 & 5.4 & 103.4 & 13.7 \\
\hline Male $_{\mathrm{HC}}$ & 9 & 88.9 & 12.0 & 44.9 & 5.8 & 85.0 & 14.3 \\
\hline Female $_{\mathrm{WP}}$ & 8 & 100.0 & 9.6 & 59.0 & 4.7 & 100.3 & 9.5 \\
\hline Male $_{W P}$ & 8 & $120.1 \mathrm{de,f}$ & 16.2 & $65.0 \mathrm{e}, \mathrm{f}$ & 7.6 & $116.9 \mathrm{e}, \mathrm{f}$ & 14.2 \\
\hline
\end{tabular}

a Significant difference MI / SH.

b Significant difference Ml / HC.

d Significant difference MI / WP.

c Significant difference SH / HC.

e Significant difference SH / WP.

${ }^{\dagger}$ Significant difference HC / WP.

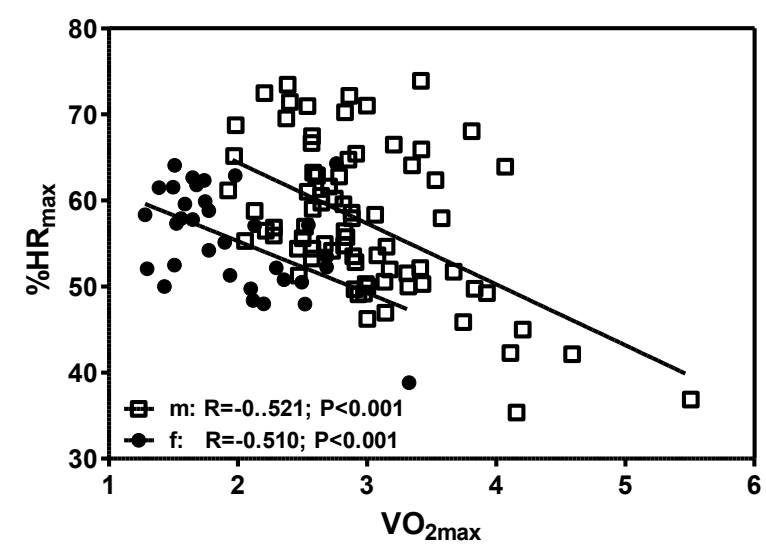

Figure 2. Percentage of maximal ergometer heart rate $\left(\% \mathrm{HR}_{\max }\right)$ during 8-hour shift workand maximal oxygen uptake $\left(\mathrm{VO}_{2 \max }\right)$ in the incremental cycle ergometer exercise test among male $(\mathrm{m})$ and female $(\mathrm{f})$ employees.

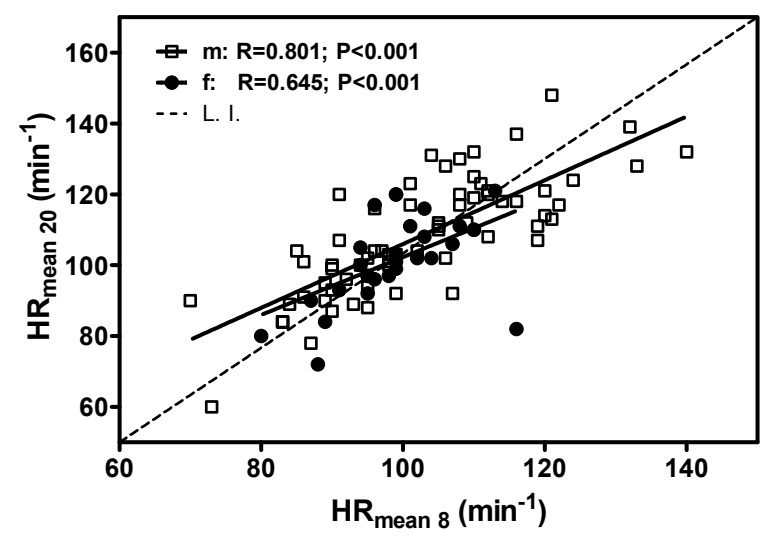

Figure 3. Relationship between mean heart rate during 20 minutes of oxygen uptake measures $\left(\mathrm{HR}_{\text {mean } 20}\right)$ and during a whole 8-hour shift $\left(\mathrm{HR}_{\text {mean }}\right)$ among male $(\mathrm{m})$ and female $(\mathrm{f})$ employees. plans (17). One way to define heavy work is to use EE during work, as is done in Austria (16). Although numerous tables of EE for various tasks are available (34), the main concern about this kind of approach may be that there is a lack of EE field measures for many occupations and occupational tasks. Therefore mostly older reference values from tables are applied (19), which may not be well adapted to the changing working standards (35). The aim of our study was therefore to measure EE by means of indirect calorimetry during several different occupational tasks to prove the applicability of the limits given by law. As approximately $60 \%$ of subjects were below these limits, one may question the limits themselves. However, if this system were to be applied in the future, systematic investigations of various additional occupations suspected to be "hard work" would have to be performed to define whether this is the case. This is in line with Shephard $(20,21)$ who stated that decisions should be made upon average data for a given population. More generally, he critically mentioned that criteria have to be defined for hard work and employees should be trained for such work.

It was shown that exercise performance and especially low fitness may be a critical component $(4,5$, 7-9), which does not define an occupation as "hard work" per se if only the fitness level of employees is too low for the task-specific requirements. Our data showed a significant relationship between exercise performance in the ergometer test $\left(\mathrm{P}_{\max }, \mathrm{VO}_{2 \max }, \mathrm{VT}_{1}, \mathrm{VT}_{2}\right)$ and workload-related strain during an 8-hour shift, indicating that not only the work but also the individual aerobic performance is relevant in defining hard work. Employees with a higher exercise performance had lower $\% \mathrm{HR}_{\max }$ compared to their less-fit counterparts, independent of 
Table 5. Work energy expenditure (EE), percentage of oxygen uptake $\left(\% \mathrm{VO}_{2}\right)$. [WEE=work energy expenditure; $\mathrm{N}_{<1400 / 2000}=$ number of tested subjects with activity work energy expenditure under $1400 / 2000 \mathrm{kcal} ; \mathrm{E}_{\mathrm{kcal}}$ calc=calculated $\mathrm{EE}$ from heart rate during workshift $\left(\mathrm{HR}_{\mathrm{Sh}}\right)$ and $\mathrm{VO}_{2}$ at exercise Test; $\% \mathrm{VO}_{2 \operatorname{max~Sh}}=\% \mathrm{VO}_{2}$ during work on maximal oxygen uptake during exercise test; $\% \mathrm{VO}_{2 \mathrm{VT} 1 \mathrm{Sh}}=\% \mathrm{VO}_{2}$ during work on oxygen uptake at the first ventilatory threshold; $\% \mathrm{VO}_{2 \mathrm{VT} 2 \mathrm{Sh}}=\% \mathrm{VO}_{2}$ during work on oxygen uptake at the second ventilatory threshold; $\mathrm{MI}=$ metal industries; $\mathrm{SD}=$ standard deviation; $\mathrm{SH}=$ slaughterhouse work; WP=waste processing; $\mathrm{HC}=$ healthcare business]

\begin{tabular}{|c|c|c|c|c|c|c|c|c|c|c|c|c|c|c|}
\hline & \multicolumn{2}{|c|}{$\mathrm{EE}_{\text {kcal }}$} & \multicolumn{2}{|c|}{$W E_{\text {kcal }}$} & \multicolumn{2}{|c|}{$\% \mathrm{~N}_{<1400 / 2000}$} & \multicolumn{2}{|c|}{$\mathrm{EE}_{\mathrm{kcal}} \mathrm{calc}$} & \multicolumn{2}{|c|}{$\% \mathrm{VO}_{2 \max S h}$} & \multicolumn{2}{|c|}{$\% \mathrm{VO}_{2 V T 1 \text { Sh }}$} & \multicolumn{2}{|c|}{$\% \mathrm{VO}_{2 \mathrm{VT} 2 \mathrm{Sh}}$} \\
\hline & Mean & SD & Mean & SD & $\%$ & $\mathrm{~N}$ & Mean & SD & Mean & SD & Mean & SD & Mean & SD \\
\hline Females & 1695.2 & 637.7 & 1248.7 & 608.9 & 63.6 & 21 & 1739.7 & 376.6 & 38.2 & 13.9 & 70.8 & 27.7 & 46.3 & 16.5 \\
\hline Males & 2451.7 & 734.9 & 1863.8 & 732.3 & 55.7 & 44 & 2308.5 & 782.0 & 39.4 & 13.7 & 78.8 & 28.5 & 49.9 & 18.1 \\
\hline Female $_{\mathrm{MI}}$ & 1669.8 & 703.2 & 1222.1 & 646.4 & 66.7 & 6 & 1540.4 & 388.7 & 46.1 & 15.6 & 86.2 & 28.7 & 55.7 & 17.3 \\
\hline Male $_{\mathrm{MI}}$ & 2436.7 & 773.9 & 1861.4 & 776.2 & 64.5 & 20 & 2114.5 & 521.9 & $43.3^{a}$ & 14.3 & $89.5^{a}$ & 30.4 & 54.9 a & 18.9 \\
\hline Female $_{\mathrm{SH}}$ & 1717.3 & 244.2 & 1327.5 & 259.1 & 50.0 & 1 & 1507.4 & 591.0 & 32.2 & 28.7 & 51.7 & 42.4 & 38.5 & 33.9 \\
\hline Male $_{S H}$ & 2589.1 & 726.1 & 1986.0 & 716.8 & 38.7 & 12 & 2121.1 & 592.3 & $39.6^{b}$ & 12.6 & $76.3^{b}$ & 22.4 & $49.9^{b}$ & 14.8 \\
\hline Female $_{\mathrm{HC}}$ & 1685.5 & 451.2 & 1219.2 & 438.8 & 57.1 & 8 & 1868.6 & 330.5 & 32.8 & 10.0 & 62.2 & 21.6 & 39.4 & 12.0 \\
\hline Male $_{\mathrm{HC}}$ & 2016.5 & 505.1 & 1421.8 & 489.3 & 88.9 & 8 & 2339.9 & 577.7 & 22.5 & 7.2 & 42.5 & 13.5 & 27.1 & 8.5 \\
\hline Female $_{W P}$ & 1596.6 & 728.3 & 1171.3 & 695.0 & 87.5 & 7 & 1796.3 & 321.0 & 40.3 & 11.6 & 73.2 & 28.7 & 49.8 & 14.7 \\
\hline Male $_{W P}$ & 2268.2 & 613.0 & 1697.1 & 643.0 & 50.0 & 4 & $3751.9^{c, d, e}$ & 1004.7 & $43.7^{\mathrm{e}}$ & 10.5 & $88.2^{e}$ & 21.6 & $56.4^{\mathrm{e}}$ & 14.7 \\
\hline
\end{tabular}

a Significant difference MI / HC.

b Significant difference SH / HC

' Significant difference MI / WP

d Significant difference SH / WP

e Significant difference HC / WP

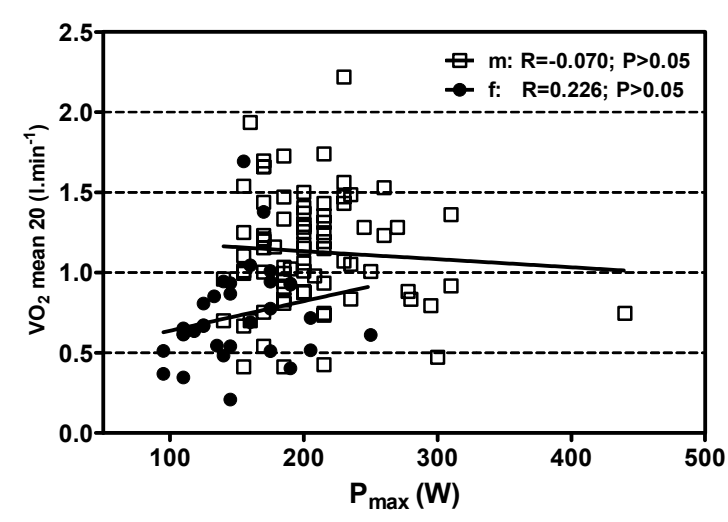

Figure 4. Mean oxygen uptake performing work $\left(\mathrm{VO}_{2 \text { mean20 }}\right)$ related to maximal cycle ergometer power output $\left(P_{\max }\right)$ among male $(\mathrm{m})$ and female (f) employees. Reference limits are presented as dotted lines.

occupation and gender (figure 2). No significant relationship between 8-hour EE and $\mathrm{P}_{\max }$ was found (figure 5 ) as well as between the BMI and the $\% \mathrm{HR}_{\max }$ among male subjects (data not shown). Although $\% \mathrm{HR}_{\max }$ was not significantly different between male and female employees, $\% \mathrm{HR} \mathrm{VT}_{1}$ and $\% \mathrm{HR} \mathrm{VT}_{2}$ were significantly different, with men working at a higher percentage of $\mathrm{VT}_{1}$ and $\mathrm{VT}_{2}$ than women. This may indicate different working strategies among male and female employees within the same job description.

It has been shown that HR may be applied as an indirect measure of EE (36). Ergometer tests have been conducted on every subject to establish a valid relationship between individual $\mathrm{HR}$ and $\mathrm{O}_{2}$ uptake in standard ergometer tests because $\mathrm{HR}$ is strongly dependent on age and shows large inter-individual variations even in the same age group $(15, \mathrm{p} 167)$. Our data confirmed this variability of the HR response and clearly showed the limits of applying only HR. Applying the $\mathrm{HR}-\mathrm{VO}_{2}$ relationship from standard ergometer tests may give reliable EE data from HR measures only in cases of standard conditions during work as the mean difference between measured and calculated EE was found to be $<5 \%$ in our study. However, in cases of severe stress (psychological, time, or heat stress) this $\mathrm{HR}-\mathrm{VO}_{2}$ relationship may not be valid (37). From this point of view, $\mathrm{O}_{2}$ uptake measures during work should be conducted $(15, \mathrm{p} 508)$.

Future research should focus on the relationship of the employee's individual aerobic capacity related to the specific strain of their work $(10,13)$. To define hard work by absolute limits of EE, additional large scale investigations for occupations suspected as hard work have to be conducted. The use of HR measures is only applicable if the true $\mathrm{HR}_{\max }$ of subjects is known and the relationship between $\mathrm{HR}$ and $\mathrm{O}_{2}$ uptake can be established (36).

\section{Concluding remarks}

Exercise performance was in the range of normal standards for most of the participants. There was a significant age-related decline of absolute HR values and an increase in $\% \mathrm{HR}_{\max }$ during the 8-hour work shift indicating increasing strain with age among both male and female employees. EE assessed by means of indirect calorimetry was found to be in the range expected for each occupation, but most of the subjects' work was below the limits given by law despite being defined as 


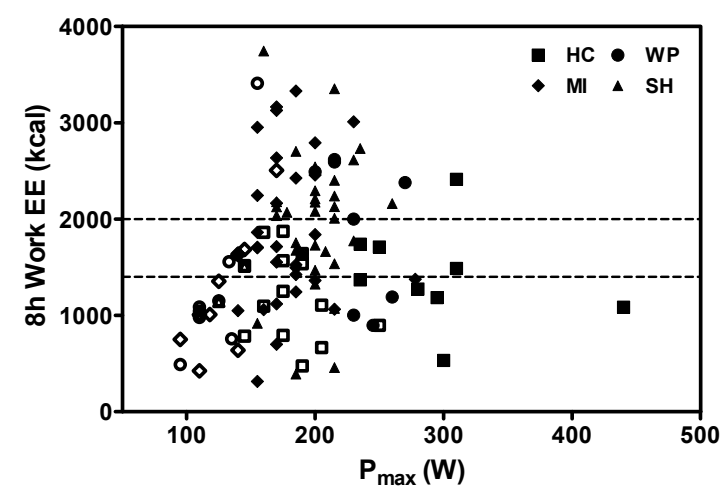

Figure 5. Estimated 8-hour working energy expenditure (8-hour work $E E)$ related to maximal cycle ergometer power output $\left(P_{\max }\right)$ among male (closed symbol) and female (open symbol) employees. Reference limits for male $(2000 \mathrm{kcal})$ and female $(1400 \mathrm{kcal})$ employees are presented as dotted lines. [HC=healthcare; WP=waste processing; $\mathrm{Ml}=$ metal industry; $\mathrm{SH}=$ slaughterhouse work.]

hard work, which calls into question the applicability of these EE limits.

Oxygen consumption during work between $33-50 \%$ of $\mathrm{VO}_{2 \max }$ may be suggested as an overall acceptable limit for eight hours of work. Therefore, $\mathrm{VT}_{1}$ may be set as the upper limit for heavy workloads for short time periods (including brakes) but should not be exceeded as it represents the workload that does not activate anaerobic metabolism (11).

The legal definition of heavy workload by mean working EE per 8-hour work shift applies to all investigated occupations, however, a substantial proportion of workers may not fulfill the criterion if applied individually. Alternative definitions of heavy workload in terms of absolute $\mathrm{O}_{2}$ consumption or EE relative to cardiorespiratory fitness lead to similar classification results for the investigated occupations.

\section{References}

1. Ilmarinen J, Costa G. Ageing of the working population in the European Union Med Lav. 2000;91(4):279-95.

2. Chan G, Tan V, Koh D. Ageing and fitness to work. Occup Med. 2000;50(7):483-91.

3. Gall B, Parkhouse W. Changes in physical capacity as a function of age in heavy manual work. Ergonomics. 2004;47(6):671-87. http://dx.doi.org/10.1080/00140130410 001658691 .

4. Ha M, Park J. Shiftwork and metabolic risk factors of cardiovascular disease. J Occup Health 2005;47(2):89-95. http://dx.doi.org/10.1539/joh.47.89.

5. Krause N, Brand RJ, Kaplan GA, Kauhanen J, Malla S, Tuomainen TP, Salonen, JT. Occupational physical activity, energy expenditure and 11-year progression of carotid atherosclerosis. Scand J Work Environ Health. 2007;33(6): 405-24. http://dx.doi.org/10.5271/sjweh.1171

6. Krause N, Brand RJ, Kauhanen J, Kaplan GA, Syme SL, Wong CC, Jukka T, Salonen, JT. Work time and 11-year progression of carotid atherosclerosis in middle-aged Finnish men. Prev Chronic Dis. 2009;6(1):A13.

7. Hannerz H, Tüchsen F, Spangenberg S, Albertsen K. Industrial differences in disability retirement rates in Denmark, 19962000. Int J Occup Med Environ Health. 2004;17(4):465-71.

8. Karpansalo M, Maninnen P, Lakka TA, Kauhanen J, Rauramaa R, Salonen JT. Physical workload and risk of early retirement: prospective population-based study among middle-aged men. J Occup Eniron Med. 2002;44(10):930-9. http://dx.doi. org/10.1097/00043764-200210000-00012.

9. Karpansalo M, Lakka TA, Manninen P, Kauhanen J, Rauramaa $\mathrm{R}$, Salonen JT. Cardiorespiratory fitness and risk of disability pension: a prospective population based study in Finnish men. Occup Environ Med. 2003;60(10):765-9. http://dx.doi. org/10.1136/oem.60.10.765.

10. Ilmarinen J, Loujevaara V, Korhonen $\mathrm{O}$, Nygård $\mathrm{CH}$, Hakola $\mathrm{T}$, Suvanto S. Changes in maximal cardiorespiratory capacity among aging municipal employees. Scand J Work Environ Health. 1991;17 Suppl 1:99-109.

11. Ilmarinen J. Job design for the aged with regard to decline in their maximal aerobic capacity: Part II - The scientific basis for the guide. Int J Ind Ergon. 1992;10:65-77. http://dx.doi. org/10.1016/0169-8141(92)90049-6.

12. Wu HC, Wang MJ. Relationship between maximum acceptable work time and physical workload. Ergonomics. 2002;45(4):280 9. http://dx.doi.org/10.1080/00140130210123499.

13. Jørgensen K. Permissible loads based on energy expenditure measurements. Ergonomics. 1985;28(1):365-9. http://dx.doi. org/10.1080/00140138508963145.

14. Bink B. The physical working capacity in relation to working time and age. Ergonomics. 1962;5:25-8.http://dx.doi. org/10.1080/00140136208930548.

15. Astrand PO, Rodahl K, Dahl HA, Stromme SB. Textbook of Work Physiology. Physiological Bases of Exercise. 4th ed. Human Kinetics, Champaign, Il. 2003.

16. Hard work act of 2006 (Schwerarbeiterverordnung 2006), Pub.L.No. 2006-II-104 (Mar 9, 2006).

17. Ilmarinen J, Tuomi $\mathrm{K}$, Eskelinen L, Nygård $\mathrm{CH}$, Huuhtanen P, Klockars M. Background and objectives of the Finnish research project on aging workers in municipal occupations. Scand J Work Environ Health. 1991;17 Suppl 1:7-11.

18. Ilmarinen J. Towards a longer and better working life: a challenge of work force ageing. Med Lav. 2006;97(2): 143-7.

19. Spitzer H, Hettinger T, Kaminsky G. Tafeln für den Energieumsatz bei körperlicher Arbeit [Tables of energy expenditure at work]. REFA; $6^{\text {th }}$ ed. Berlin, Köln:Beuth. 1982.

20. Shephard, RJ. Assessment of occupational fitness in the context of human rights legislation. Can J Sports Sci. 1990;15(2): 89-95.

21. Shephard RJ. Occupational demand and human rights. Public 
safety officers and cardiorespiratory fitness. Sports Med. 1991;12(2):94-109. http://dx.doi.org/10.2165/00007256199112020-00003.

22. Tammelin T, Näyhä S, Rintamäki H, Zitting P. Occupational physical activity is related to physical fitness in young workers. Med Sci Sports Exerc. 2002;34(1):158-65. http:// dx.doi.org/10.1097/00005768-200201000-00024.

23. Sluiter JK. High-demand jobs: age-related diversity in work ability? Appl Ergon. 2006;37(4):429-40. http://dx.doi. org/10.1016/j.apergo.2006.04.007.

24. Ceesay SM, Prentice AM, Day K, Murgatroyd PR, Goldberg GR, Scott W, Spurr GB. The use of heart rate in the estimation of energy expenditure: a validation study of indirect whole body calorimetry. Br J Nutr. 1989;61(2):175-86. http://dx.doi. org/10.1079/BJN19890107.

25. International Labour Organisation (ILO): International Standard Classification of Occupation (internet). [cited 2011 Jan 17]. Geneva: ILO. Available from: http://www.ilo.org/ public/english/bureau/stat/isco/.

26. American College of Sports Medicine. ACSM's Guidelines for Exercise Testing and Prescription. 7th ed. Lippincott William \& Wilkins; 2006.

27. Wonisch M, Berent R, Klicpera M, Laimer H, Marko C, Pokan R, et al. Praxisleitlinien Ergometrie [Practice Guidelines for Ergometry]. J Kardiol. 2008;15: 3-17.

28. Meyer T, Lucía A, Earnest CP, Kindermann W. A conceptual framework for performance diagnosis and training prescription from submaximal gas exchange parameters-theory and application. Int J Sports Med. 2005;26 Suppl 1: 38-48. http:// dx.doi.org/10.1055/s-2004-830514.

29. Binder RK, Wonisch M, Corra U, Cohen-Solal A, Vanhees L, Saner H, Schmid JP. Methodological approach to the first and second lactate threshold in incremental cardiopulmonary exercise testing. Eur J Cardiovasc Prev Rehabil. 2008;15(6):726-34. http://dx.doi.org/10.1097/

\section{HJR.0b013e328304fed4.}

30. Beaver WL, Wasserman K, Whipp BJ. A new method for detecting anaerobic treshold by gas exchange. J Appl Physiol 1986;60(6);2020-7.

31. Wilmore JH, Costill DL. Physiology of Sport and Exercise. 2nd ed. Human Kinetics, Champaign, Il., 1999.

32. Mifflin MD, St Jeor ST, Hill L, Scott BJ, Daugherty SA, Koh YO. A new predictive equation for resting energy expenditure in healthy individuals. Am J Clin Nutr. 1990;51(2):241-7.

33. World Health Organization (WHO): Health Factors in Workers under Conditions of Heat Stress. Technical Report Series 412. Geneva: WHO, 1969.

34. Ainsworth BE, Haskell WL, Whitt MC, Irwin ML, Swartz AM, Strath SJ, et al Compendium of physical activities: an update of activity codes and MET intensities. Med Sci Sports Exerc. 2000;32(9 Suppl):498-504. http://dx.doi. org/10.1097/00005768-200009001-00009.

35. Tuomi K, Ilmarinen J, Seitsamo J, Huuhtanen P, Martikainen R, Nygard CH, Klockars M. Summary of the Finnish research project (1981-1992) to promote the health and work ability of aging workers. Scand J Work Environ Health. 1997; 23 Suppl 1:66-71.

36. Bouchard DR, Trudeau F. Reliability of the assessment of the oxygen/heart rate relationship during a workday. Appl Ergon. 2007;38(5):491-7. http://dx.doi.org/10.1016/j. apergo.2006.10.002.

37. Hilloskorpi H, Fogelholm M, Laukannen R, Pasanen M, Oja P, Mänttäri A, Natri A. Factors affecting the relationship between heart rate and energy expenditure during exercise. Int J Sports Med. 1999;20(7):438-43. http://dx.doi. org/10.1055/s-1999-8829.

Received for publication: 3 February 2011 